\title{
Comparison of gluteus medius strength between individuals with obesity and normal-weight individuals: a cross-sectional study
}

Rafael Ratti Fenato ${ }^{1,2^{*}}$, Allan Cezar Faria Araujo $^{3}$ and Ana Tereza Bittencourt Guimarães ${ }^{4}$

\begin{abstract}
Background: The hip abductor muscles, primarily the gluteus medius, play an important role in stabilizing the pelvis during gait. Gluteus medius weakness is associated with biomechanical changes and musculoskeletal disorders. Individuals with obesity can have great difficulty maintaining abductor muscular function due to being overweight and possibly experiencing a decrease in muscle mass. However, it is still unclear whether the musculature of person with obesity can compensate for these changes. Therefore, the aim of this study was to compare gluteus medius strength between individuals with obesity and normal-weight individuals using a digital hand-held dynamometer.

Methods: Twenty-five participants with obesity $\left(\mathrm{BMl}>35 \mathrm{~kg} / \mathrm{m}^{2}\right)$ were matched for sex, age, and height with normal-weight individuals. Gluteus medius strength was measured by a single examiner using a belt-stabilized hand-held digital dynamometer placed on the knee of the individuals positioned in lateral decubitus. Three measurements were recorded with rest intervals, and only the highest value measured for each limb was used for analysis. The differences between pairs were calculated, and the normality of the data was assessed using the Shapiro-Wilk test $(p<0.05)$. The matrices of the variables were standardized and analysed using principal component analysis (PCA).
\end{abstract}

Results: For the strength variables (Newtons) on both sides, no significant differences were detected between the groups $(p>0.05)$. However, significant differences were detected in these variables between the groups $(p<0.05)$ when the measurements were normalized to body weight (Newtons/kilograms). PCA indicated that both the absolute and normalized values of strength are lower in participants with obesity than in normal-weight.

Conclusions: These findings suggest that people with obesity could have the same or less strength (PCA) to move more mass, which may imply a relative weakness that induces functional limitations.

Keywords: Obesity, Hip, Muscle weakness

\footnotetext{
* Correspondence: rafaelfenato@yahoo.com.br

'Faculty of Medicine, Federal University of Paraná, Paraná, Toledo, Brazil

² Voglia Ortopedia, Maranhão Street, 790, Room 09, Centro, Paraná 85801-050

Cascavel, Brazil

Full list of author information is available at the end of the article
}

(c) The Author(s). 2021 Open Access This article is licensed under a Creative Commons Attribution 4.0 International License, which permits use, sharing, adaptation, distribution and reproduction in any medium or format, as long as you give appropriate credit to the original author(s) and the source, provide a link to the Creative Commons licence, and indicate if changes were made. The images or other third party material in this article are included in the article's Creative Commons licence, unless indicated otherwise in a credit line to the material. If material is not included in the article's Creative Commons licence and your intended use is not permitted by statutory regulation or exceeds the permitted use, you will need to obtain permission directly from the copyright holder. To view a copy of this licence, visit http://creativecommons.org/licenses/by/4.0/ The Creative Commons Public Domain Dedication waiver (http://creativecommons.org/publicdomain/zero/1.0/) applies to the data made available in this article, unless otherwise stated in a credit line to the data. 


\section{Background}

Hip abductor muscles play an important role in stabilizing the pelvis during gait, which allows the body to effectively maintain balance and lower limb mobility [1]. This group of muscles includes the gluteus medius, gluteus minimus, and tensor fasciae latae, but the gluteus medius is the main hip abductor muscle $[2,3]$.

The magnitude of force required by the hip abductors to stabilize the pelvis is approximately 2.5 times the individual's body weight [4], as confirmed by in vivo studies [5]. Thus, the strength of the abductor muscles together must be higher than the individual's body weight. When there is enough strength to support the individual's body weight, his or her gait pattern is normal, and the joints work properly. If weight overload or muscle weakness occurs, an adaptation of the upper body will be triggered in an attempt to bring the centre of gravity closer to the centre of hip rotation.

Maintaining the strength of the gluteal musculature can be very challenging for subjects with obesity. When a three-dimensional gait analysis of subjects with obesity was performed, larger hip adduction, associated with marked ankle eversion, was observed during the terminal stance and pre-balance phases [6]. These findings are similar to those found in individuals with missing gluteal musculature, which leads to a pathological gait pattern, defined as Trendelenburg gait [7], as well as reduced abduction strength, an external rotation tendency, and internal rotation weakness of the lower limbs [8]. There is clearly an imbalance, which has a negative influence on gait parameters [9]. These changes lead to anteroposterior and mediolateral instability of the upper body and thus functional limitations and a predisposition to injuries [10-12].

Both overweight and individuals with obesity still suffer from the metabolic effects of adipose tissue on the muscular system. A decrease in anabolic hormones, such as growth hormones [13], and an increase in proinflammatory cytokines alter muscle metabolism. Both factors affect the amino acid balance, neuromuscular activation, and signalling pathways in the caspase cascade [13-16]. Finally, a decrease in muscle mass establishes a condition called sarcopenic obesity [13], in which the inflammatory cytokines produced by visceral fat are able to alter muscle metabolism and trigger a vicious cycle involving degeneration and a reduction in skeletal muscle quality [17-19].

It is very important to assess gluteus medius strength in individuals with obesity in clinical practice. Weakness in this muscle is associated with not only biomechanical changes but also musculoskeletal system disorders, such as hip arthrosis, lower back pain, knee arthrosis, and patellofemoral syndrome [20-26].

We conducted this study to compare the strength of the main gait-stabilizing muscle of individuals with obesity and normal-weight individuals. The aims of this study were to measure the strength of abductor muscles, especially the gluteus medius, using a digital hand-held dynamometer and to compare two groups of matched individuals: participants with obesity and participants with normal-weight.

\section{Methods}

The present study is observational, quantitative, analytical, and cross-sectional. The UNIOESTE Human Research Ethics Committee (\#1.180.202) approved it in July 2015. The patients provided written formal consent in accordance with the rules of the ethics committee.

Individuals with obesity who were beginning ambulatory follow-ups at the Obesity and Bariatric Surgery Service in the Western Paraná University Hospital (Cascavel, Paraná, Brazil) were included in the study. These individuals were of both sexes, were aged 20 to 60 years old, had grade II and III obesity, and had a body mass index (BMI) higher than $35 \mathrm{~kg} / \mathrm{m}^{2}$ [27, 28]. The exclusion criteria were pregnancy, an orthopaedic disease of the lower limbs, locomotor system pain or sequelae, paresthesia or weakness in the lower limbs, orthostatic or walking pain, heart disease, or other diseases with restricted functional capacity.

For comparison, a group of normal-weight individuals (control group) was recruited, with a BMI below $24.9 \mathrm{~kg} / \mathrm{m}^{2}$, a value considered normal. They were matched with the individuals with obesity by sex, age and height.

For the calculation of the sample size, a large effect size (0.8) was assumed due to the homogeneity of the group of patients from the Obesity and Bariatric Surgery Service of HUOP, and a type I error equivalent to 0.05 and a power of analysis with Student's t-test of 0.80 were used. Based on these parameters, a total sample size of 54 was needed.

A single examiner evaluated the participants in an attempt to prevent analysis bias between observers from affecting the results. Weight (kilograms, kg) and height (meters, m) were measured.

All subjects eligible for the research were evaluated according to the exclusion criteria by assessing their clinical history and targeted physical examination findings. Individuals with pregnancy, an orthopaedic disease of the lower limbs, pain or sequelae in the locomotor system, self-reported paresthesia or weakness in the lower limbs, orthostatic or walking pain, heart disease or other diseases with restricted functional capacity were excluded. 
The physical screening examination included an assessment of sensory disturbances, passive leg elevation and an assessment of hip joint pain after hip flexion and internal rotation and knee flexion and extension. Individuals who exhibited any signs suggestive of a pathology related to the impairment of the locomotor system were excluded.

Gluteus medius strength was measured using a handheld digital dynamometer (MICROFET2, Draper, USA), which has been shown to have high reliability in testretest studies [29]. The device was positioned $5 \mathrm{~cm}$ proximal to the knee joint line, a technique adapted from the reports of Hislop and Montgomery [30-32]. The participant was positioned on a stretcher in lateral decubitus with a knee pad to avoid adduction, with slightly extended hips and anterior inclination of the pelvis, so that the strength components predominantly related to the gluteus medius could be measured (Fig. 1). The upper limbs remained relaxed to prevent them from affecting the strength test. The dynamometer was attached to the stretcher by using a rigid band, eliminating the need for the examiner to apply a resistance force. The participants were verbally asked to exert a maximum force against the device for $5 \mathrm{~s}$, and after a 30second rest interval, a new trial was performed. Three measurements were made, and only the highest value measured was used for analysis. After the analysis, the participant was repositioned for the measurement of the contralateral gluteus medius. The right side was always tested first.

\section{Statistical analysis}

The intraclass correlation coefficient (ICC) was calculated to assess the reproducibility of the evaluator's measurements. A pilot study was performed to evaluate the strength of both the right (RGM) and left (LGM) gluteus medius muscles of six selected individuals. Homogeneity of the measures was observed, with ICC values for the right and left sides equivalent to 0.9675 and 0.9288 , respectively.

The data were tabulated in the Microsoft Excel $2013^{\circ}$ program. Pairing was performed between groups by similarity in the variables sex, age, and height. The differences between pairs were calculated, and the normality of the data was assessed using the Shapiro-Wilk test. The comparisons between pairs were performed using the paired-samples t-test since all the variables were normally distributed. The statistical tests were performed using the $\mathrm{R}$ Core Team program ( $\mathrm{R}$ Core Team, 2018) with a significance level of 0.05 .

Then, matrices of the variables were standardized and analysed using principal component analysis (PCA). With PCA, the factor loads are defined as the correlations of each variable with the factor composition, where the factor is a new variable defined by the set of factor loads. This analysis did not consider the pairings but rather the subdivision of two large groups in an attempt to differentiate them. The factorial loads resulting from the main components were evaluated in terms of statistical significance using the independent-samples t-test.

\section{Results}

After the reliability of the measurements was assessed, 95 individuals were examined: 35 participants with obesity and 60 participants with normal-weight. Of these, 8 individuals from the obesity group and 3 individuals from the control group did not meet the selection criteria and were excluded. Two individuals with obesity were also excluded due to their short stature, which made it difficult to correlate their findings with the normal-weight individuals. Ultimately, 25 control-obesity pairs were formed, matched by gender and similarity in age and height. A total of 32 normal-weight participants were excluded because they could not be paired (Fig. 2).

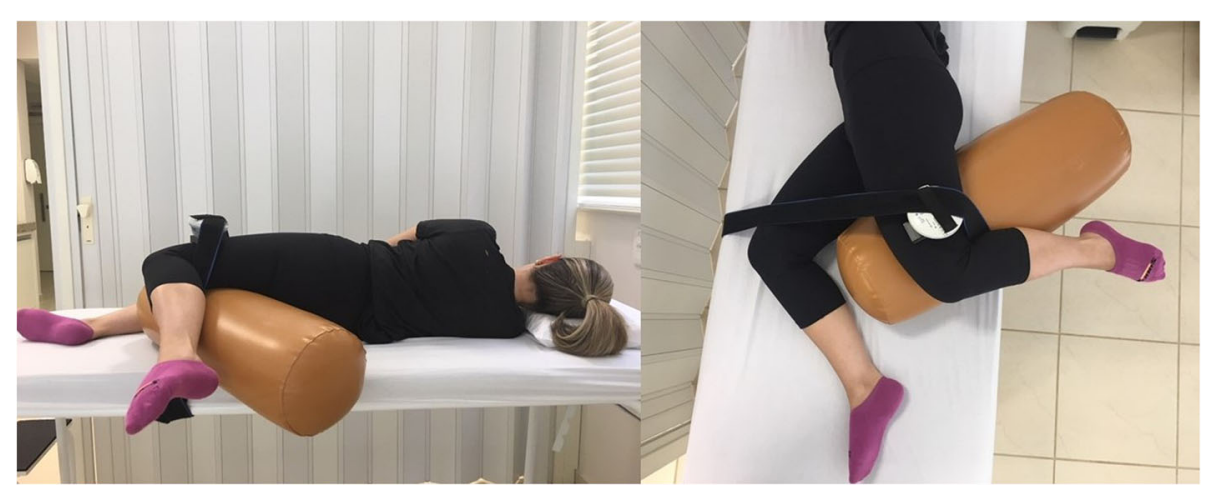

Fig. 1 a Posterior and $\mathbf{b}$ superior view of the position used to measure gluteus medius strength 


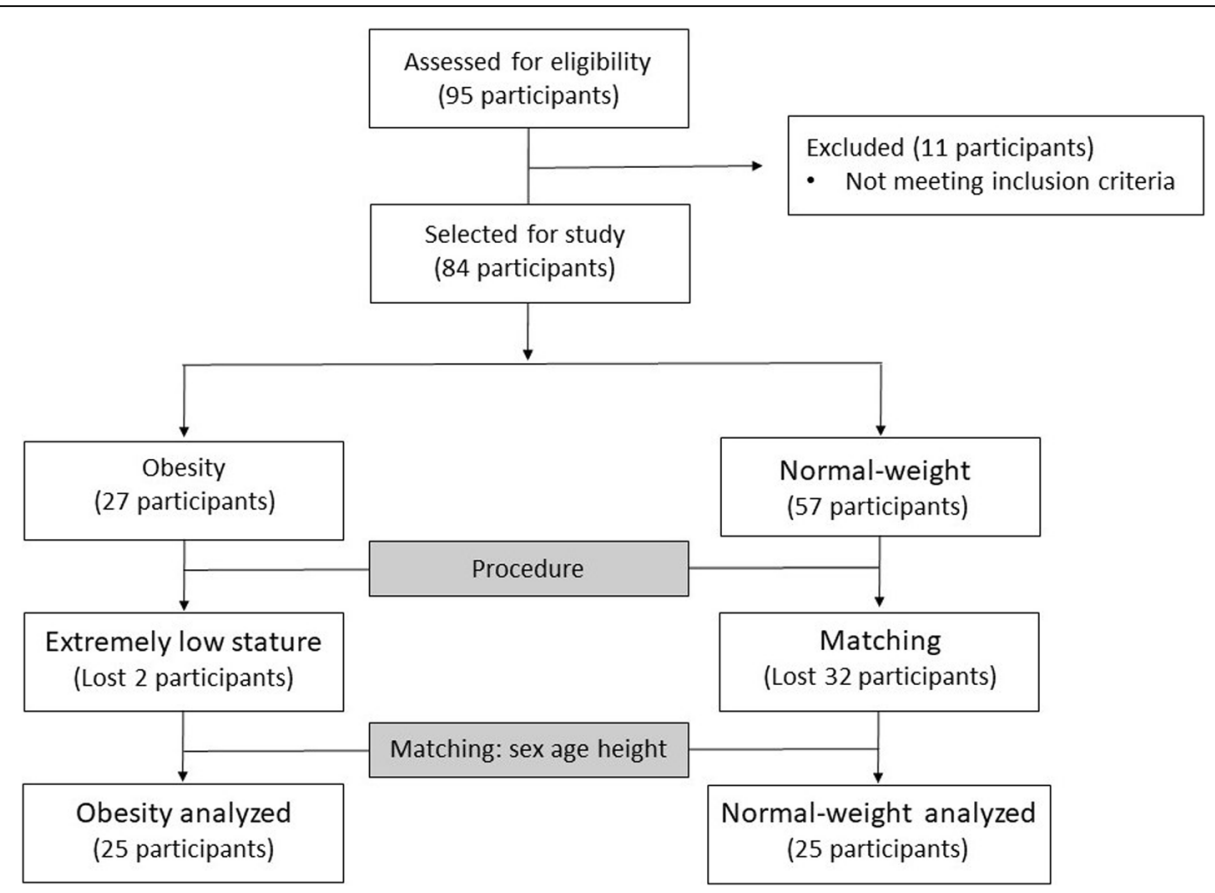

Fig. 2 Diagrams showing a schematic summary of the participants recruited for this study

Fifty individuals, including 4 (8\%) males and 46 (92\%) females, were included in the analysis, number that do not reach the recommended sample size because of the pairing. The variables of sex, age, and height were considered statistically equivalent between the obesity and control groups $(p>0.05)$. The weight and BMI variables showed statistically significant differences between pairs $(p<0.0001$; Table 1). An additional file shows the data in more detail [see Additional file 1].

For the strength $(\mathrm{N})$ of the RGM and LGM, no significant differences were detected between groups $(p>0.05)$. However, when the measurements were normalized to the body weight $(\mathrm{N} / \mathrm{kg})$, significant differences were detected in these to variables between groups $(p<0.05)$ (Table 2; Fig. 3).
Considering only the values normalized by weight among the individuals included in the analysis, the multivariate assessment verified the separation of the two groups: the control and obesity groups. In this study, pairing was not considered, only the division of two samples in relation to the force variable was considered to differentiate them. The first main component was defined as the variation in the strength of the RGM and LGM normalized to body weight (in $\mathrm{N} / \mathrm{kg}$ ) (eigenvalue $=3.03$; variability $=75.67 \%$ ) and was directly related to the separation of the two groups analysed. The second main component was defined by the absolute muscle forces of the RGM and LGM (in N), which were also directly related (eigenvalue $=0.72$; variability $=$ 18.04\%; Fig. 4).

Table 1 Descriptive data of the pairs regarding age, height, weight, and BMI. P-value corresponding to the paired-samples t-test

\begin{tabular}{lllllll}
\hline Variable & Group & Minimum & Maximum & Mean & Standard deviation & $P$-value \\
\hline Age & Obesity & 20.000 & 60.000 & 43.600 & 9.785 & 0.407 \\
& Control & 23.000 & 57.000 & 42.880 & 10.647 & 0.091 \\
Height & Obesity & 1.500 & 1.930 & 1.600 & 0.090 \\
& Control & 1.480 & 1.900 & 1.599 & 19.111 \\
Weight & Obesity & 89.000 & 165.000 & 114.600 & 8.825 \\
& Control & 45.000 & 80.000 & 58.068 & 5.126 \\
BMI & Obesity & 36.616 & 56.008 & 44.604 & 2.032 \\
\hline
\end{tabular}


Table 2 Descriptive results for the absolute strength and strength normalized to body weight of the RGM and LGM. $P$-value corresponding to the paired-samples t-test

\begin{tabular}{llrlc}
\hline & & \multicolumn{1}{c}{ Control } & \multicolumn{1}{l}{ Obesity } & $P$-value \\
\hline Strength (N) & RGM & $292.0 \pm 94.5$ & $256.2 \pm 104.2$ & 0.149 \\
& LGM & $290.7 \pm 76.6$ & $261.1 \pm 118.0$ & 0.231 \\
Strength / Weight & RGM & $51.5 \pm 15.6$ & $22.7 \pm 8.0$ & $<0.0001$ \\
(N / Kg) & LGM & $51.8 \pm 15.0$ & $23.1 \pm 9.1$ & $<0.0001$ \\
\hline
\end{tabular}

The factor loads of the main component 1 , which represents the variation in muscle forces in $\mathrm{N} / \mathrm{kg}$, showed significant differences between pairs $(t=5.14$; $p<0.0001$; Fig. 5a), indicating that the strength values normalized to weight (in $\mathrm{N} / \mathrm{kg}$ ) of the RGM and LGM were higher in the normal-weight individuals. The factor loads of main component 2 also showed significant differences between groups $(t=-8.63$; $p<$ 0.0001 ), indicating that the strength values of the RGM and LGM in $\mathrm{N}$ tend to be reduced in subjects with obesity (Fig. 5b).

\section{Discussion}

Measuring the strength of hip muscles can be a difficult task. Several limitations have been reported regarding this task, including limited access to accurate equipment, difficulties in positioning the patient properly, variations in the support area on which the device is placed, the possibility of patient movement, and inconsistency in the verbal stimulus intensity [29]. Manual muscle testing is the most commonly used method for this purpose since it is easy and quick to perform, is free of charge, and does not require equipment [33]. Nevertheless, this test is subjective and descriptive, so it leads to low reliability and frequently overestimates the actual strength. The isokinetic dynamometer is the gold standard device for assessing muscle strength, with an exact and secure evaluation toll [34]. Because of the cost of an isokinetic testing device and difficulties in routine clinical testing, there is evidence that supports the clinical use of the hand-held dynamometer in routine medical
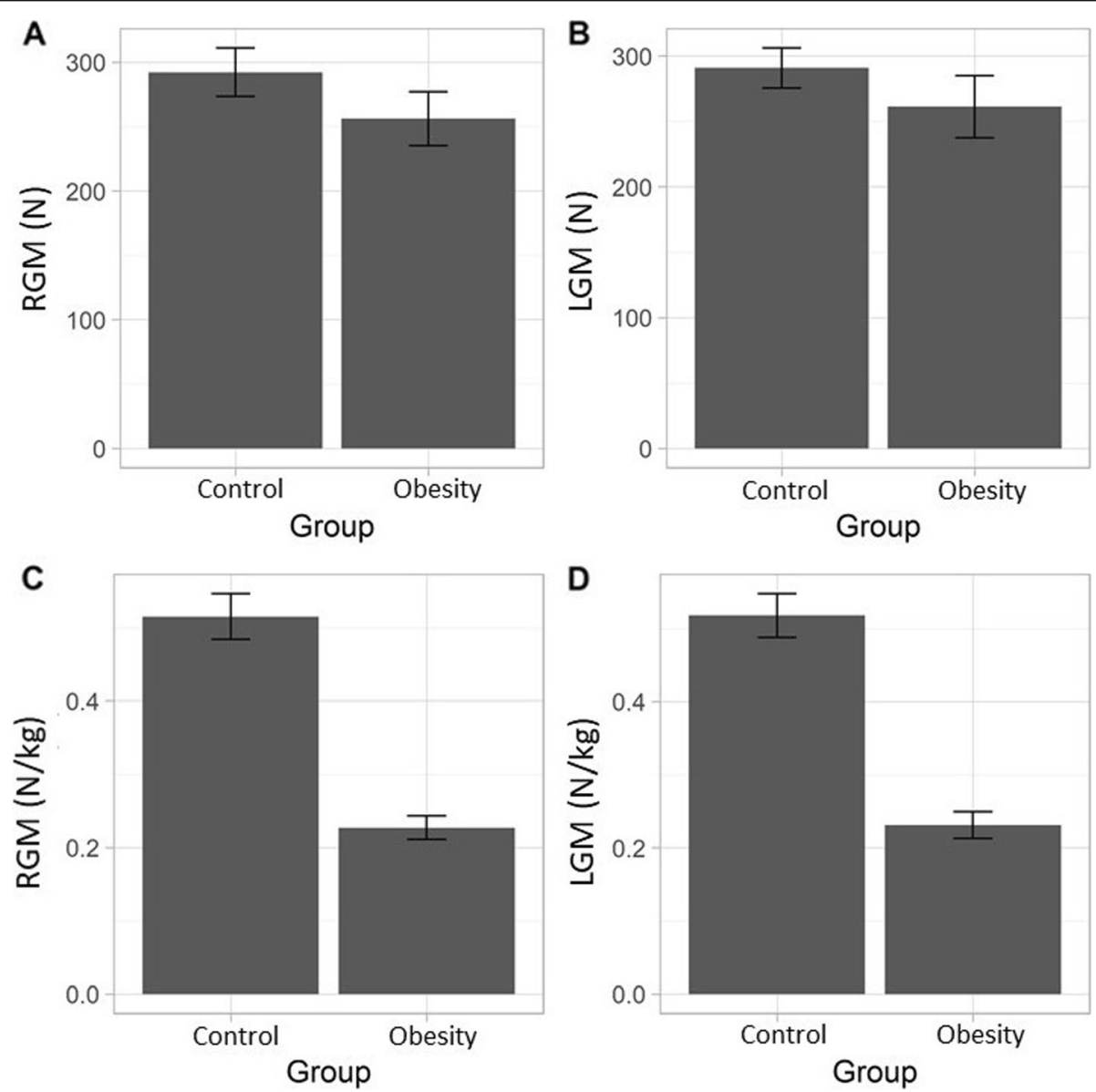

Fig. 3 Comparative graphs showing the difference between the RGM and LGM. Legends: a RGM in N; b LGM in N; c RGM in N/kg; d LGM in $\mathrm{N} / \mathrm{kg}$ 


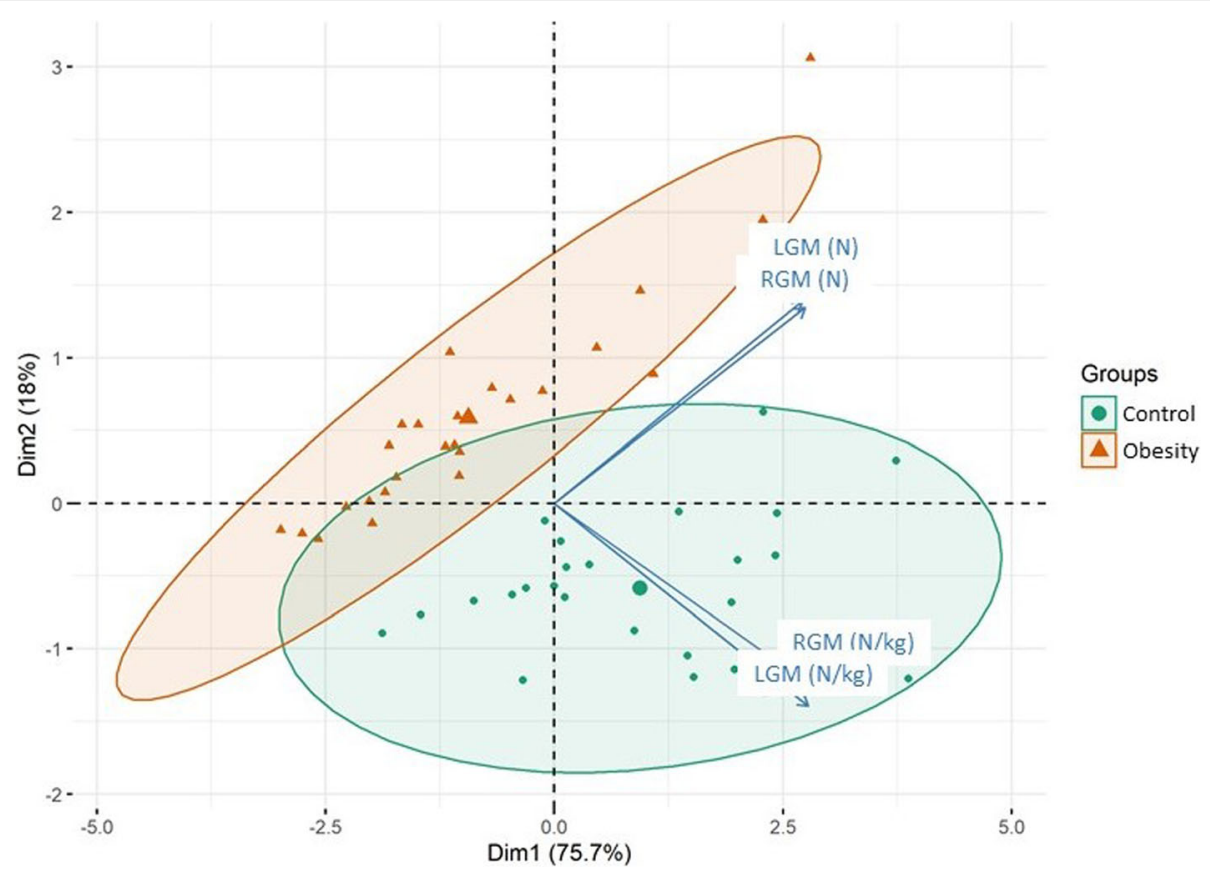

Fig. 4 Ordering diagram of the principal components. Legends: RGM - right gluteus medius strength in N/kg; LGM - left gluteus medius strength in N/kg; RGM N - right gluteus medius strength in N; LGM N - left gluteus medius strength in N. Control (green ellipse) and obesity (orange ellipse) groups
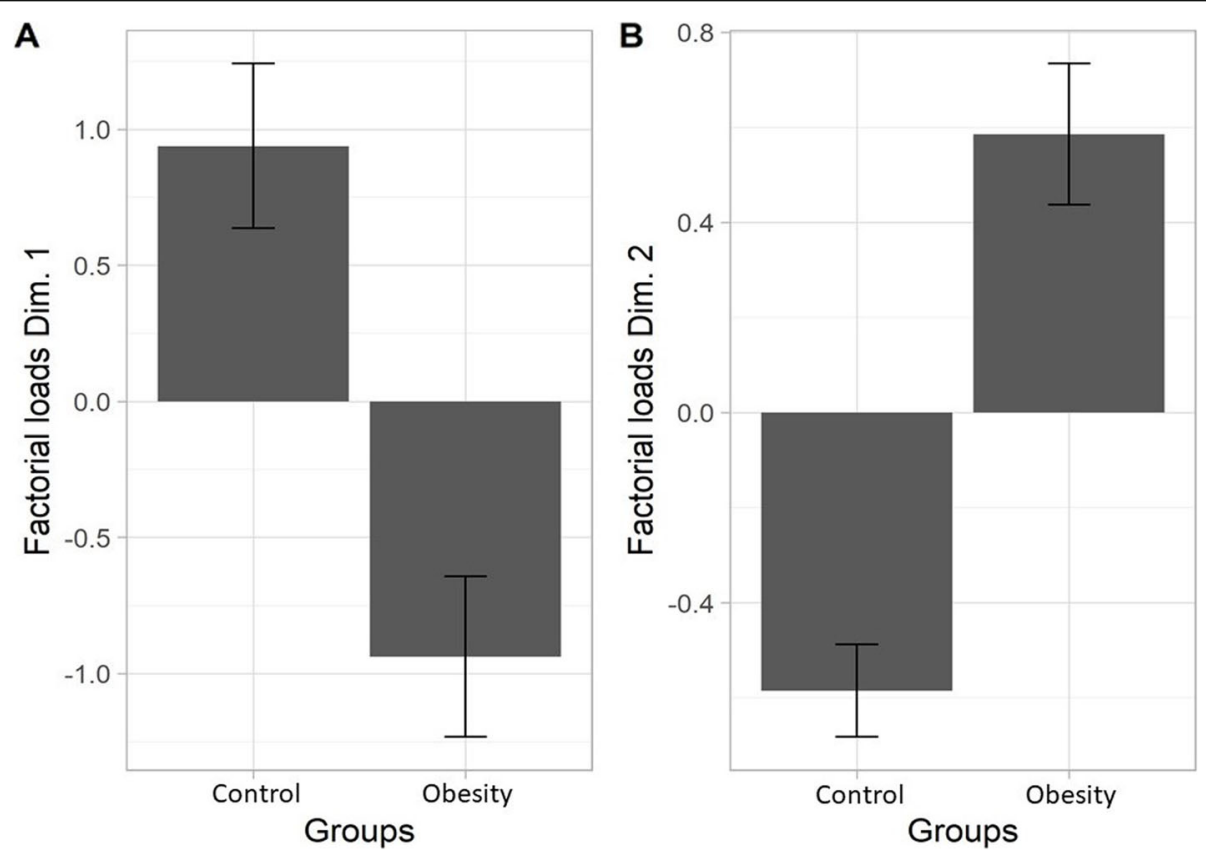

Fig. 5 Means and standard errors of factor loads of the main components for the control and obesity groups. Legends: a first main component; b second main component 
examinations [35]. This device measures strength in an objective, precise and sensitive way [36]. However, the hand-held dynamometer is not without limitations, especially because this method is dependent on external adjustments to improve result validity and reliability [37]. It is a valid method when stabilized by a belt, and although these devices do not yield the same measures as isokinetic dynamometers, the values for hip muscle groups are correlated [38]. Thus, we chose to use a digital dynamometer stabilized by a brace to measure of the strength of the gluteus medius muscle.

The determination of the force required by the abductor muscles to balance the body in a standing position depends on two variables: pelvic anatomy and body weight [27]. In the present study, since individuals were paired in relation to sex, age, and height, it is assumed that there was a similarity in the pelvic anatomy between the pairs. Since the examination was performed by a single examiner, variability in the measurements due to differences in the technique used were not observed. Weight was the only relevant variable that could interfere with the strength data.

In the present study, individuals with obesity did not present a statistically significant difference in gluteus medius strength compared to normal-weigth individuals $(p>0.05)$. The absolute strength values were $292.0 \mathrm{~N}$ for the RGM and $290.7 \mathrm{~N}$ for the LGM in the control group. In the obesity group, the values were 256.2 and $261.1 \mathrm{~N}$, respectively.

In a literature review, Benfica et al. [28] reported the hip abductor muscle strength values in individuals aged between 50 and 59 years old to be $208.12 \mathrm{~N}$ for the dominant limb and $203.27 \mathrm{~N}$ for the nondominant limb in women and $305.97 \mathrm{~N}$ for the dominant limb and 298.49 $\mathrm{N}$ for non-dominant limbs in men. In the present study, this variation in the measurements can be explained by the age differences among the individuals included in the analysis, differences in sex, and differences related to the measurement technique.

The age range of the participants (from 20 to 60 years old) was chosen since it corresponds to an economically active group in whom movement disorders can greatly impact function and work. Additionally, individuals over 60 years of age may have reduced muscle mass and function [39].

It is worth noting that the study population in the present study consisted predominantly of women (92\%) for reasons of convenience and that abductor muscle strength varies between sexes. Women have lower abductor muscle strength, which corresponds to a higher risk of developing musculoskeletal pathologies [40].

In contrast to these findings in our study, some authors suggest that the antigravity muscles of subjects with obesity generate higher absolute forces [41-44]. Increased muscle strength is described as a beneficial adaptation to obesity, with excess body weight acting as a chronic training stimulus for daily activities [44].

Several studies have reported increased knee extension strength in individuals with obesity, with values varying from 10 to $30 \%$ higher than those of normal-weight individuals [45]. However, gait analyses in individuals with obesity have shown a shorter stride length with a strategy involving quadriceps overloading and decreased hamstring activation $[6,46]$. Due to gait changes, obesity can cause mechanical adaptations that favour the use of the strongest muscles and minimize the use of the weakest ones.

Regarding the gluteus medius, Lerner et al. [11] reported that subjects with obesity have higher absolute strength during gait and correlated this change with an increased BMI, reflecting the same theory of overload adaptation. These data were not confirmed by the gluteus medius strength analysis performed in the present study since there was no difference in the isometric strength values between the groups tested $(p>0.05)$. An analysis using nuclear magnetic resonance suggested that the gluteal musculature presents an increase in fat infiltrate as the BMI increases [47]. Although obesity increases muscle mass in the short term in young individuals, lipid infiltration in skeletal muscle can reduce the incorporation of amino acids into muscle proteins over time, with a decrease in total muscle mass [17]. It is possible that the long-term effect of obesity on muscle tissue overlaps with this weight stimulus on antigravity muscles and culminates in muscle loss over time [15]. This possibility may justify the findings of our study.

When the gluteus medius strength values were normalized to body weight, there was a significant difference $(p<0.05)$ between groups, which indicates that individuals with obesity have relative gluteus medius weakness compared to normal-weight individuals. Obesity results in larger and lower quality muscles, which have the same absolute strength and power as smaller muscles in thin individuals [48]. However, individuals with obesity generally struggle to move their body mass. A lack of strength can culminate in functional adaptations and imbalance, predisposing these individuals to injuries [10, 49].

Although some studies have suggested that individuals with obesity have higher absolute strength, they have less relative strength in some muscles, such as the quadriceps [50, 51]. Lafortuna et al. [52] also corroborated these data when they evaluated lower limb muscle strength through a leg-press exercise. Compared with normal-weight individuals, the subjects with obesity were stronger, but when the values were normalized by muscle mass, this difference disappeared.

When Lerner et al. [11] normalized the strength of the gluteal muscles by weight, there was no relevant 
difference between the obesity and normal-weight groups. Regarding muscle mass, the authors also reported that individuals with obesity required greater gluteal muscle strength for normal gait. This evidence is relevant since it suggests that individuals with obesity need stronger gluteal muscles, causing them to be more susceptible to fatigue. Thus, it was expected that overweight individuals have higher muscle strength to maintain balance while standing or walking. This fact was not proven by the results in the present study. When strength was normalized to body weight, the group with obesity had relative weakness in the gluteus medius muscle $(p<0.05)$. It can be concluded that strength alone does not seem to be an adequate parameter for assessing the abductor musculature since more than half of the world's population is overweight and these strength values can be overestimated $[53,54]$.

The gluteal strength of individuals with obesity is a relevant factor since these two variables, obesity and weakness, are independently associated with musculoskeletal system changes [20-26, 55]. Moreover, according to new scientific evidence, muscle strength is inversely and independently associated with all-cause mortality [56]. Some authors even recommend the use of an algorithm to remove the dependence on body size and to more appropriately compare the strength of the hip muscles across individuals since it cannot be concluded that the force is directly proportional to body weight $[57,58]$.

When the statistical analysis of the factor loads was performed, it was possible to differentiate the two distinct groups for all gluteus medius force variables, regardless of whether they were normalized to body weight. This finding indicates that both the absolute strength values and those related to weight were different, constituting two distinct groups: the obesity group and the normal-weight or control group.

The present study has some limitations. First, despite the sample size being close to the recommended value in the sample calculation, we consider that it would be necessary to increase the number of subjects to reduce the effect size of the analysis. Therefore, additional studies are needed to confirm and increase the generalizability of the results found. Second, the study population was predominantly composed of women $(92 \%)$. Although this limitation did not interfere with the conclusions since the individuals were paired between groups, it would be interesting to increase the number of men since this sex are stronger than women. Activity level between groups should have been another variable and was not reported in this study. Additional studies are needed to prove whether there are morphological and functional changes in obesity gluteal muscles that may justify gait imbalances and associations with musculoskeletal disorders.

\section{Conclusions}

The findings of the present study suggest that although subjects with obesity have the same absolute strength of the gluteus medius muscle as normal-weight individuals, when the strength is normalized as a function of body weight, it is possible to state that these individuals have such a weaker gluteus medius muscle. Since obesity is an epidemic, as the majority of the world's population is overweight, it is recommended that individuals strengthen the gluteal muscles in relation to their weight, especially since obesity and weakness are independently associated with musculoskeletal system changes.

\section{Abbreviations}

BMI: Body mass index; cm: Centimetres; ICC: Intraclass correlation coefficient; kg: Kilograms; LGM: Left gluteus medius muscle; m: Metres; N: Newtons; N/ kg: Newtons per kilogram; PCA: Principal component analysis; RGM: Right gluteus medius muscle; UNIOESTE: Universidade Estadual do Oeste do Paraná; USA: United States of America

\section{Supplementary Information}

The online version contains supplementary material available at https://doi. org/10.1186/s12891-021-04470-8.

Additional file 1. Data of paired pairs

\section{Acknowledgements}

Not applicable.

Authors' contributions

RRF - performed the examination of the individuals and was a major contributor in writing the manuscript. ACFA - conducted the research and guided the data collection. ATBG - analyzed and interpreted the individuals data. All authors read and approved the final manuscript.

Authors' information

Not applicable.

Funding

There were no sources of funding for the reported research.

Availability of data and materials

The datasets used and analysed during the current study are available in Additional file 1.

\section{Declarations}

Ethics approval and consent to participate

The UNIOESTE (Universidade Estadual do Oeste do Paraná) Human Research Ethics Committee approved the researche in July 2015 by the number 1.180.202.

The patients provided written formal consent in accordance with the rules of the ethics committee.

Consent for publication

All individuals participating in this research signed an informed consent form prior to their inclusion in the study.

A written informed consent for publication of the images was obtained. 


\section{Competing interests}

The authors declare that they have no competing interests.

\section{Author details}

${ }^{1}$ Faculty of Medicine, Federal University of Paraná, Paraná, Toledo, Brazil. ${ }^{2}$ Voglia Ortopedia, Maranhão Street, 790, Room 09, Centro, Paraná 85801-050 Cascavel, Brazil. ${ }^{3}$ Obesity and Bariatric Surgery Center, University Hospital of the Western Paraná State University, Cascavel, Paraná, Brazil. ${ }^{4}$ Center of Biological and Health Sciences, Western Paraná State University, Paraná, Cascavel, Brazil.

\section{Received: 9 February 2020 Accepted: 10 June 2021}

Published online: 25 June 2021

\section{References}

1. Zaghloul A, Mohamed EM. Hip joint: embryology, anatomy and biomechanics. BJSTR. 2018;12:9304-18.

2. Correa TA, Crossley KM, Kim hJ, Pandy MG. Contributions of individual muscles to hip joint contact force in normal walking. J Biomech. 2010;43: 1618-22.

3. John CT, Seth A, Schwartz MH, Delp SL. Contributions of muscles to mediolateral ground reaction force over a range of walking speeds. J Biomech. 2012;45:2438-43.

4. Frankel VH, Pugh JW. Biomechanics of the hip. In: Tronzo RG. Surgery of the hip joint. New York: Springer; 1984. pp. 115-31.

5. Byrne DP, Mulhall KJ, Baker JF. Anatomy \& biomechanics of the hip. Open Sports Med J. 2010;4:51-7.

6. Lai PP, Leung AK, Li AN, Zhang M. Three-dimensional gait analysis of obese adults. Clin Biomech. 2008;23(Suppl 1):2-6.

7. Callanghan JJ, Rosenberg AG, Rubash HE. The adult hip. 2nd ed. Philadelphia: Lippincott Williams \& Wilkins; 2007.

8. Harrasser N, Banke I, Gollwitzer H, Wilken F, Toepfer A, von Eisenhart-Rothe R, et al. Gluteale insuffizienz: pathogenese, diagnostik und therapie. Z Orthop Unfall. 2016;154:140-7.

9. Silva-Hamu TC, Formiga CK, Gervásio FM, Ribeiro DM, Christofoletti G, de França Barros J. The impact of obesity in the kinematic parameters of gait in young women. Int J Gen Med. 2013;6:507-13.

10. Capodaglio P, Cimolin V, Tacchini E, Parisio C, Galli M. Balance control and balance recovery in obesity. Curr Obes Rep. 2012;1:166-73.

11. Lerner ZF, Board WJ, Browning RC. Effects of obesity on lower extremity muscle function during walking at two speeds. Gait Posture. 2014;39:97884.

12. Rosso V, Agostini V, Takeda R, Tadano S, Gastaldi L. Influence of BMI on gait characteristics of young adults: 3D evaluation using inertial sensors. Sensors. 2019;19:4221.

13. Roubenoff R. Sarcopenic obesity: does muscle loss cause fat gain? Lessons from rheumatoid arthritis and osteoarthritis. Ann N Y Acad Sci. 2000;904 553-7.

14. Narici MV, Maffulli N. Sarcopenia: characteristics, mechanisms and functional significance. Br Med Bull. 2010;95:139-59.

15. Schrager MA, Metter EJ, Simonsick E, Ble A, Bandinelli S, Laurentani F, et al. Sarcopenic obesity and inflammation in the InCHIANTI study. J Appl Physiol. 2007;102:919-25

16. Erskine RM, Tomlinson DJ, Morse Cl, Winwood K, Hampson P, Lord JM, et al. The individual and combined effects of obesity- and ageing-induced systemic inflammation on human skeletal muscle properties. Int J Obes. 2017:41:102-11

17. Masgrau A, Mishellany-Dutour A, Murakami H, Beaufrère AM, Walrand S, Giraudet $C$, et al. Time-course changes of muscle protein synthesis associated with obesity-induced lipotoxicity. J Physiol. 2012;590:5199-210.

18. Kim TN, Park MS, Ryu JY, Choi HY, Hong HC, Yoo HJ, et al. Impact of visceral fat on skeletal muscle mass and vice versa in a prospective cohort study: the Korean Sarcopenic Obesity Study (KSOS). PLoS One. 2014;9:e115407.

19. Shultz SP, Byrne NM, Hills AP. Musculoskeletal function and obesity: implications for physical activity. Curr Obes Rep. 2014;3:355-60.

20. Cooper NA, Scavo KM, Strickland KJ, Tipayamongkol N, Nicholson JD, Bewyer DC, et al. Prevalence of gluteus medius weakness in people with chronic low back pain compared to healthy controls. Eur Spine J. 2016;25: 1258-65.
21. Bewyer KJ, Bewyer DC, Messenger D, Kennedy CM. Pilot data: association between gluteus medius weakness and low back pain during pregnancy. lowa Orthop J. 2009;29:97-9.

22. Hinman RS, Hunt MA, Creacy MW, Wrigley TV, McManus FJ, Bennell KL. Hip muscle weakness in individuals with medial knee osteoarthritis. Arthritis Care Res. 2010;62:1190-3.

23. Rowe J, Shafer L, Kelley K, West N, Dunning T, Smith R, et al. Hip strength and knee pain in females. N Am J Sports Phys Ther. 2007;2:164-9.

24. Bolgla LA, Malone TR, Umberger BR, Uhl TL. Comparison of hip and knee strength and neuromuscular activity in subjects with and without patellofemoral pain syndrome. Int J Sports Phys Ther. 2011;6:285-96.

25. Sims KJ, Richardson CA, Brauer SG. Investigation of hip abductor activation in subjects with clinical unilateral hip osteoarthritis. Ann Rheum Dis. 2002; 61:687-92.

26. Loureiro A, Mills PM, Barrett RS. Muscle weakness in hip osteoarthritis: a systematic review. Arthritis Care Res. 2013;65:340-52.

27. Daniel M, Hornová J, Doubrava K, Tomanová M. Biomechanical analysis of local and global strengthening of gluteus medius. Turk J Phys Med Rehabil. 2017;63:283-5

28. Benfica PDA, Aguiar LT, Brito SAF, Bernardino LHN, Teixeira-Salmela LF, Faria CDCM. Reference values for muscle strength: a systematic review with a descriptive meta-analysis. Braz J Phys Ther. 2018;22:355-69.

29. Bohannon RW. Reference values for extremity muscle strength obtained by hand-held dynamometry from adults aged 20 to 79 years. Arch Phys Med Rehabil. 1997;78:26-32.

30. Hislop HJ, Montgomery J. Daniels and Worthingham's muscle testing: techniques of manual examination. 8th ed. Philadelphia: Saunders; 2007.

31. Mior SA. Muscle testing, techniques of manual examination. J Can Chiropr Assoc. 1985;29:49.

32. Ireland ML, Willson JD, Ballantyne BT, Davis IM. Hip strength in females with and without patellofemoral pain. J Orthop Sports Thys Ther. 2003;33:671-6.

33. Cuthbert SC, Goodheart GJ Jr. On the reliability and validity of manual muscle testing: a literature review. Chiropr Osteopat. 2007;15:4.

34. Stark T, Walker B, Phillips JK, Fejer R, Beck R. Hand-held dynamometry correlation with the gold standard isokinetic dynamometry: a systematic review. PM\&R. 2011:3:472-9.

35. Kolber MJ, Cleland JA. Strength testing using hand-held dynamometry. Phys Ther Rev. 2005;10:99-112

36. Jackson SM, Cheng MS, Smith AR Jr, Kolber MJ. Intrarater reliability of hand held dynamometry in measuring lower extremity isometric strength using a portable stabilization device. Musculoskelet Sci Pract. 2017;27:137-41.

37. Hansen EM, McCartney CN, Sweeney RS, Palimenio MR, Grindstaff TL. Handheld Dynamometer Positioning Impacts Discomfort During Quadriceps Strength Testing: A Validity and Reliability Study. Int J Sports Phys Ther. 2015;10(1):62-8.

38. Martins J, da Silva JR, da Silva MRB, Bevilaqua-Grossi D. Reliability and validity of the belt-stabilized handheld dynamometer in hip- and kneestrength tests. J Athl Train. 2017;52:809-19.

39. Artaud F, Singh-Manoux A, Dugravot A, Tavernier B, Tzourio C, Elbaz A. Body mass index trajectories and functional decline in older adults: Three-City Dijon cohort study. Eur J Epidemiol. 2016;31:73-83.

40. Sugimoto D, Mattacola CG, Mullineaux DR, Palmer TG, Hewett TE. Comparison of isokinetic hip abduction and adduction peak torques and ratio between sexes. Clin J Sport Med. 2014;24:422-8.

41. Maffiuletti NA, Ratel S, Sartorio A, Martin V. The impact of obesity on in vivo human skeletal muscle function. Curr Obes Rep. 2013;2:251-60.

42. Tomlinson DJ, Erskine RM, Morse Cl, Winwood MK, Onambélé-Pearson G. The impact of obesity on skeletal muscle strength and structure through adolescence to old age. Biogerontology. 2016;17:467-83.

43. Abdelmoula A, Martin V, Bouchant A, Walrand S, Lavet C, Taillardat M, et al. Knee extension strength in obese and nonobese male adolescents. Appl Physiol Nutr Metab. 2012;37:269-75.

44. Garcia-Vicencio S, Coudeyre E, Kluka V, Cardenoux C, Jegu AG, Fourot AV et al. The bigger, the stronger? Insights from muscle architecture and nervous characteristics in obese adolescent girls. Int J Obes. 2015;40:245-51.

45. Bollinger LM. Potential contributions of skeletal muscle contractile dysfunction to altered biomechanics in obesity. Gait Posture. 2017;56:100-7.

46. Amiri P, Hubley-Kozey CL, Landry SC, Stanish WD, Astephen Wilson JL. Obesity is associated with prolonged activity of the quadriceps and gastrocnemii during gait. J Electromyogr Kinesiol. 2015;25:951-8. 
47. Pacicco T, Ratner S, Xi Y, Yokoo T, Fetzer D, Oz OK, et al. Pelvic muscle size and myosteatosis: relationship with age, gender, and obesity. Indian J Radiol Imaging. 2019;29:155-62.

48. Tallis J, Hill C, James RS, Cox VM, Seebacher F. The effect of obesity on the contractile performance of isolated mouse soleus, EDL, and diaphragm muscles. J Appl Physiol. 2017;122:170-81.

49. Teasdale N, Simoneau M, Corbeil P, Handrigan G, Tremblay A, Hue O. Obesity alters balance and movement control. Curr Obes Rep. 2013;2:23540.

50. Duvigneaud N, Matton L, Wijndaele K, Deriemaeker P, Lefevre J, Philippaerts $R$, et al. Relationship of obesity with physical activity, aerobic fitness and muscle strength in Flemish adults. J Sports Med Phys Fitness. 2008;48:20110.

51. Maffiuletti NA, Jubeau M, Agosti F, De Col A, Satorio A. Quadriceps muscle function characteristics in severely obese and nonobese adolescents. Eur J Appl Physiol. 2008;103:481-4.

52. Lafortuna CL, Maffiuletti NA, Agosti F, Sartorio A. Gender variations of body composition, muscle strength and power output in morbid obesity. Int J Obes. 2005;29:833-41.

53. OECD Obesity Update. 2017. Organization for Economic Co-operation and Development, Paris. 2017. http://www.oecd.org/health/obesity-update.htm. Accessed 9 Feb 2020.

54. Francisco V, Pérez T, Pino J, López V, Franco E, Alonso A, et al. Biomechanics, obesity, and osteoarthritis. The role of adipokines: when the levee breaks. J Orthop Res. 2018;36:594-604.

55. Volaklis KA, Halle M, Meisinger C. Muscular strength as a strong predictor of mortality: a narrative review. Eur J Intern. 2015;26:303-10.

56. Kushner RF, Kahan S. Introduction: the state of obesity in 2017. Med Clin North Am. 2018;102:1-11.

57. Jaric S. Muscle strength testing: use of normalisation for body size. Sports Med. 2002;32(10):615-31.

58. Bazett-Jones DM, Cobb SC, Joshi MN, Cashin SE, Earl JE. Normalizing hip muscle strength: establishing body-size-independent measurements. Arch Phys Med Rehabil. 2011;92(1):76-82.

\section{Publisher's Note}

Springer Nature remains neutral with regard to jurisdictional claims in published maps and institutional affiliations.

Ready to submit your research? Choose BMC and benefit from:

- fast, convenient online submission

- thorough peer review by experienced researchers in your field

- rapid publication on acceptance

- support for research data, including large and complex data types

- gold Open Access which fosters wider collaboration and increased citations

- maximum visibility for your research: over $100 \mathrm{M}$ website views per year

At $\mathrm{BMC}$, research is always in progress.

Learn more biomedcentral.com/submissions 